\title{
Culinary List Form in the Experimental Poetry of 1960s Finland: Literary Menus and Recipes
}

\author{
Juri Joensuu
}

A reader interested in different approaches or eras of avant-garde and experimental literature-whether he or she reads concrete poetry, Samuel Beckett's or Georges Perec's prose, works of American postmodernism, or conceptual writing of the new millennium-is likely to stumble across enumeration, the list form. Reasons for the list's almost symbiotic compatibility with experimental approaches and techniques are numerous, as the literary list can serve a variety of functions. One can hypothesize that experimental writers easily, even instinctively, adopt the list because the list form can produce two situations on a smaller scale that experimental writing seeks to explore on a wider scale. First, it can bring about a break from the conventional poetic or narrative norms and expectations, and second, at the same time, it can highlight writing as a material and technical

The original version of this chapter was revised. A correction to this chapter can be found at https://doi.org/10.1007/978-3-030-76970-3_14

\footnotetext{
J. Joensuu $(\bowtie)$

University of Jyväskylä, Jyväskylä, Finland

e-mail: juri.m.joensuu@jyu.fi
}

(C) The Author(s) 2022, corrected publication 2022

R. A. Barton et al. (eds.), Forms of List-Making: Epistemic, Literary, and Visual Enumeration, https://doi.org/10.1007/978-3-030-76970-3_9 
practice for recording, manipulating, and producing verbal information. And, in a more thematic sense, the list form is apt for dealing with order, hierarchy, or power, be it social, ideological, political, or systemic - themes and subject matters dear to many experimental writers. This chapter tries to explore the symbiosis of enumeration and experimental literature by introducing and analyzing a peculiar subgenre of literary lists: texts that utilize culinary list forms such as the menu and the recipe.

By the term "experimental" I refer to a variety of formal, material, technical, or conceptual approaches consciously chosen by writers to explore the processes of creation, composition, or reception, as well as literary forms, norms, and values. The root word "experiment" refers to a sciencelike model of testing, the ambition "to extend the boundaries of $[\ldots]$ artistic practice," which also "implies rejection of hide-bound traditions, values and forms" (Bray et al. 2012, 2). To do these things, experimental literature is, nonetheless, quite sensitive to its own tradition: it recycles and reworks established techniques, methods, and formal approaches of writing. Typical experimental literary devices include collage, experiments with typography and spatial design, non-linear and multimodal narration as well as the application of rules and constraints (à la $\mathrm{OuLiPo}^{1}$ )—and, intersecting with some of these, the list form.

One specific example of experimental writing can be found in menupoems. A menu can mean, first, a designed set of dishes and drinks to be consumed in a specific order. As such, the menu-the order of appetizers, main dishes, desserts, and appropriate drinks-represents a developed cultural order, which represents certain professional rules and tastes. A menu in this regard represents a meal as controlled, sociable eating and drinking. Second, menu can mean an optional list of dishes (à la carte) in a restaurant or canteen. Compared to the menu, which, according to Henry Notaker (2017, 104-105), first appeared at private dinner parties in France during the nineteenth century, the recipe has a longer and more complex genealogy. In practice, the recipe can be described as a textual formula for the purposes of preparing specific portions of food or beverages. The recipe is not necessarily textual nor culinary, but the textual form enables its two central functions: recording and consulting. ${ }^{2}$ Besides food and drink, recipes also connect to the history of medicine, drugs, naturopathy, and esoteric areas of knowledge. As textual genres, both the menu and the recipe are recognizable, practical, non-literary text types. Both of them are also lists, listing a series of dishes, ingredients, steps, and stages of production. They present (sequential) actions that are oriented toward possible future action.

Food listings have a long tradition in the history of literature. A subgenre of the literary list, food listing can be an inventory of foodstuffs, or 
part of the description of a meal, its preparation, composition, presentation, or consumption. ${ }^{3}$ Food listing can also be (a part of) a fictitious, imaginative recipes or menus, in fiction either embedded in the narration or presented as a separate list when the agent of narration is more unclear. ${ }^{4}$ In poetry, recipes or menus can be used as a recognizable epistemic form "filled" with unexpected (poetic) content. As such, enumeration is usually one of the determining factors that provokes the reader to recognize the familiar form of the recipe or the menu. The graphical and typographical principles - the ways lists accentuate texts as images - are important, also in culinary forms. Even if "literary recipes" or "literary menus" present fictitious, sometimes impossible dishes-food and drinks that could not exist in reality-still, what seems to be decisive is the way in which they transport the reality of cooking and the cultural memory of food traditions and thus also speak to the personal culinary memories of the reader.

In the literary context of the 1960s Finnish experimentalists, the use of recipe and menu forms can be considered a part of "a series of efforts to articulate new relationships between art and the rapidly changing everyday, between 'high' and 'low' and between the different discourses in society" (Veivo 2016, 773). Eating and drinking are inevitable and mundane-everyday-activities in the very sense of the word. "When we eat," food sociologists inform us, "we are not merely consuming nutrients, we are also consuming gustatory (i.e., taste-related) experiences and, in a very real sense, we are also 'consuming' meanings and symbols. Every aliment in any given human diet carries a symbolic charge along with its bundle of nutrients" (Beardsworth and Keil 1997, 51). The examples explored in this chapter expand on this notion and represent polysemic approaches to taste, status, and cultural order. Their impact rests on the clash between the mundane and the exceptional, the everyday and the fantastic. Menus and recipes offer ways to examine these relationships in symbolically coded forms.

Besides these social implications, two viewpoints from experimental poetics can be considered. First, as both recipes and menus are usually non-literary, practical forms, their inclusion and imitation in literature is strongly connected to the tendency seen in experimental writings to draw from other sources such as recovered texts, literary objet trouvés, appropriations, and re-contextualizations. These practices are found in early avant-garde techniques (e.g., Duchamp, Breton), modernist writing (e.g., Eliot, Williams), post-war American experimental poetry (e.g., Ashbery, 
Berrigan), as well as in the conceptual writing of the new millennium (see Epstein 2012). Second, one can ask in what ways the list form relates to constrained writing and procedural literature in the Oulipian sense (see endnote 1), meaning rules, methods, or other formal principles willfully chosen and imposed by the writer. The list as such is too broad a form to be accepted as a constraint in the Oulipian sense..$^{5}$ Yet, it can either be joined with a variety of Oulipian constraints or function as an essential background structure in certain instances of constrained writing. ${ }^{6}$

From the viewpoint of European or global literary studies, my material comes from uncharted territory, 1960s Finland. I hope that the alleged obscurity and marginality of my material will add insight on the versatility, universality, applicability, and incisiveness of literary lists and their areas of usage. My focus will be on the poetic usage of the list form: the tension between, on the one hand, the unity and the order inherent in the list form and, on the other hand, the free imaginative variation in the content. In my examples the list form ironizes order. Connected to this theme, the readings of the selected recipes and menus will reveal symbolic and ideological meanings that exceed their supposedly culinary content.

\section{LisTS IN THE EXPERIMENTAL LITERATURE OF 1960s FinLAND}

Before I proceed with my primary material, I will give a couple of examples of the list form in 1960s Finnish experimental literature. The aim is to offer some literary-historical context and also to consider thematic and formal similarities between these starters and the main course: four texts (two menus and two recipes) that prove exceptional in the ways they combine distinctive content with inventive use of form. The four texts chosen show a representative selection from 1960s Finnish "culinary literature." The form of the list distinguishes them from conventional and nonexperimental literature which is typically less cognizant of form.

Internationally, the 1960 s was an active decade for experimental endeavors in art and literature. Different "neo-avant-garde" activities were born around the world, the term Conceptual art was introduced in 1961, the Fluxus Manifesto was conceived by George Maciunas in 1963, and Sol LeWitt's seminal text "Paragraphs on Conceptual Art" appeared in 1967. The 1960s also marked the beginning of postmodernism in literature (McHale 2008). Concrete poetry was vibrant in Europe, but also in Latin 
America. OuLiPo was established in 1960 and consolidated its position during the decade.

Meanwhile, also the remote, in many ways still post-war and barely urban Finland "saw the rise of a new interest in the avant-garde $[\ldots]$ especially in poetry" (Veivo 2016, 772). In many respects this was something new. The period of Finnish-language modernism only really took off in the 1950s. Before World War II, attempts to translate the innovative approaches of the European Avant-gardes (Futurism, Dadaism, and Surrealism) into the Finnish context were extremely rare. Only German Expressionism had some positive reception in Finland as figures such as "the first modernist" Edith Södergran (1892-1923) and Uuno Kailas (1901-1933) show. There are many reasons for Finland's cultural hostility toward experimental literature. The legacy of the brutal civil war (1918) politicized Finnish culture for decades. Avant-gardistic arts were regarded as suspicious imported goods in the eyes of both right-wing and left-wing political groups. Together with a lack of literary tradition, a lack of urban culture, and the linguistic "outsider" status of the Fenno-Ugric language, this created a hostile climate for avant-garde, artistic innovation, and experimentation. ${ }^{7}$

But in the 1960s something changed in Finnish literature along the lines of innovation and international influences in other arts (e.g., visual arts, performance, electronic music, see Hottinen 2016). Especially the short, three-year period of the mid-decade saw a burst of some 30 works of versatile experimental literature (Joensuu 2016, 28). Besides such techniques as text collage, visual text, enhanced typography, minimalism, and different intermedial applications, the list was clearly the most recurring form in the experimental endeavors of the decade. According to Harri Veivo $(2016,773)$, the "attempts to get to grips with changes in everyday life and to navigate in the new discursive world are visible in the use or imitation of lists and catalogues." While this is probable, other kinds of motivation and functions for the use of lists can also be assumed. According to Jan Alber (2016), postmodernist literary lists (1) foreground the linguistic medium, and thus, are self-reflexive; (2) highlight (and make fun of) our need to impose order on chaos; and (3) celebrate variety and plurality. All these claims hold true also for many of the lists found in the works of 1960s Finnish experimentalists, although labeling them postmodernists would be daring. ${ }^{8}$ Still, the following examples of 1960 s Finnish list poetry demonstrate the flexibility and variability of the list form's subject matters, approaches, and effects. 
I will start with a rather abstract, almost conceptual poem which uses very non-lyrical word-lists.9 "Informaatiota" ("Information," 1966) by Brita Polttila (1920-2008) lists different acronyms of political players of the decade. For instance, "EFTA" designates the European Free Trade Association, "YK" and "NL" are the Finnish abbreviations for United Nations and Soviet Union, respectively. The ironic end phrase translates as "Come on, get real / let's go to movies!"

\title{
INFORMAATIOTA
}

\author{
EFTA \\ NATO \\ EEC \\ ANF \\ MLF \\ OAS \\ YAT \\ YK \\ TN \\ SEATO \\ USA \\ NL \\ FAO \\ MLF MLF MLF MLF YK YK TN \\ - Kuule älä viitsi intoilla \\ mennään leffaan! (Polttila 1966, 9)
}

One can compare Polttila's poem to an even more abstract, untitled poem by J. O. Mallander (b. 1944), which consists of mechanical repetitions of the Swedish words "nedräkning" (countdown) and "uppräkning" (listing), combined with the word "vidräkning" (reckoning, confrontation), which appears only once (see Mallander 1969, 64). In the book, the listing of two words fills the whole page lengthways: it extends from the text area to the upper and lower edges of the page, deliberately violating the typographical margin rules. In doing so, it suggests the infiniteness of this list: the list goes beyond the material book. Like the poem above by Brita Polttila, Mallander's poem, too, highlights the materiality of language. Stripped of its communicative and aesthetic function and turned into a sign that signifies nothing beyond its own endless perpetuation, Mallander's 
objectified language almost resembles concrete poetry. It seems as if these were compiled or produced by a machine. ${ }^{10}$ The recipe and menu poems also play with this kind of non-literary, non-lyrical, and procedural approach to writing.

As in recipes, the following poem by Kalevi Seilonen (1937-2011) seems to have a rather authoritative diction. The poem presents five rather contradictious and sometimes nonsensical statements as facts. The title is the organizing and grouping principle, binding together these five numbered main clauses.

Scientific Facts

1. Goethe had a weak understanding.

2. $97 \%$ of Finns are German.

3. Saarikoski has 12 drainpipes.

4. Finnish Broadcasting Company offends the Constitution.

5. Champignons are no champions. (Seilonen 1965, 22, original: "Tieteellisiä tosiasioita")

All the lines are concisely phrased declarative sentences that evoke the impression of being objective facts, even though they strongly claim something rather unexpected. Far from facts or scientific findings, these claims resemble, respectively, historical and logical impossibilities, inside jokes, conspiracy theories, or tongue-in-cheek opinions. The first claim on Goethe's cognitive capabilities could indicate a rebellion against Western literary values and tastes, doubled in the non-traditional form of the poem. Pentti Saarikoski (1937-1983) was a celebrity poet of the time, renowned for his bohemian lifestyle, so "12 drainpipes" might be considered as a sarcastic allusion to his industrious drinking. Furthermore, the leftist politicization of the Yleisradio (Finnish Broadcasting Company) was a widely discussed topic in the 1960s. The last sentence is a pun, which is difficult to translate. It centers on the notion of taste: the Finnish term for champignon is "delicacy mushroom" and the speaker claims that "delicacy mushrooms are no delicacy." A pun is a very different form of knowledge than a scientific fact. While the first one is simply given, the second should be the subject of investigation. The ascending numerical presentation in the lines of the poem and the use of numericals in the text $(97 \%, 12)$ ironically make use of mathematical conventions that stand in for objective knowledge, order, and hierarchy, which the very content of the "facts" 
makes redundant. It would be impossible to achieve the same structural irony (the delightful conflict between the serious form and the oddball content) without the numbered listing. It is this idea of (linear) order and logical sequence which is also typical for the formal arrangement of recipes.

The poems by Polttila and Seilonen discussed above make use of the non-literary list's documentary, "applicatory" function and transfer it to a context outside the realm of objective facts-a feature they share with the culinary lists discussed in the following section. Just as a list easily captures topical, current discourse, the same form can ironize and criticize the ideological dimensions of the content by laying bare contradictions that obviate the need for explanation. Irony is "potentially an effective strategy of oppositionality," even a passionate "mode of combat" (Hutcheon 1994, 29). This oppositionality can also be noticed in the following examples.

The first menu poem by Aronpuro in the following section uses the list as a realistic (probably facsimile) part of a collage, with both documentary and ideological tendencies. It also relies on the visual layout which the list form typically produces. The second menu poem by Lappalainen presents a bizzare menu, which documents mainly the workings of the poet's imagination. In the recipes by Hollo and Numminen the generic user-guidance of the recipes is ironized by oppositional, countercultural, spiritual, and psychedelic elements. These are reinforced by the procedural list formula of the recipe.

\section{Menus and Recipes: Four Servings}

Peltiset enkelit ("Tin Angels," 1964), the first collection of prolific experimentalist Kari Aronpuro (b. 1940), includes a five-page collage poem "Zodiac (aivofilmi)" ("Zodiac (Brain Film)"). Rich in typographical variety, the poem employs different types, signs, and symbols, while mirroring a stroll in an urban landscape, framed by all kinds of oncoming verbal stuff. In the mix there is also a menu (see Figs. 9.1 and 9.2). It resembles a genuine, discovered text representing a selection of foods in a workers' canteen ("Open from 9 to 23 "). Instead of higher culinary cultures, this à la carte from a working-class dining environment is as street-credible as the poem's references to, for instance, public transport, cigarette commercials, or an etiquette text from a cheap booze brand ("Pöytä / viinaa / Bords / brännvin"). Most dishes on the menu are affordable, mundane grub, like oat porridge, fried herrings, or pea soup. Bread, butter, and milk-cornerstones of the 1960s Nordic cuisine-are sold separately (see 
9 CULINARY LIST FORM IN THE EXPERIMENTAL POETRY OF 1960S... 195

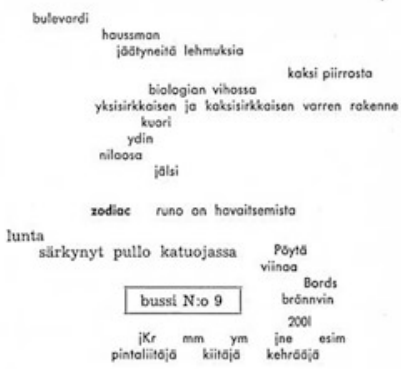

HERBERT ROSE QUARTET IN 568 Jessus

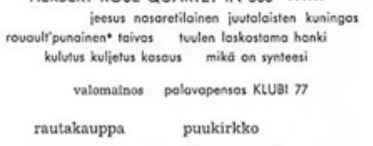

mina tulen torin poikki rönnän siivin

- Kornerup \& Wanscher: Värien kirja; lahinnă 10 B 8 32

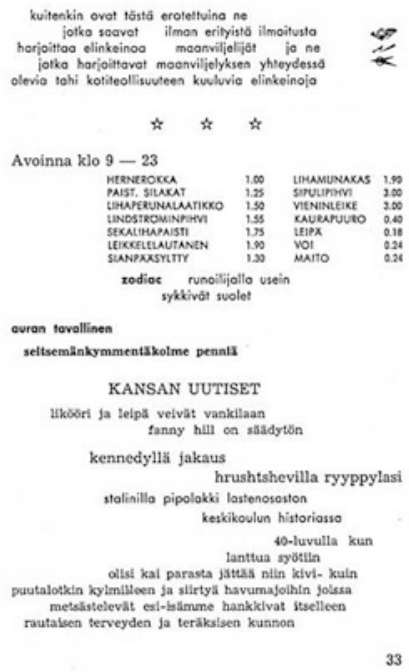

Fig. 9.1 Kari Aronpuro, "Zodiac (aivofilmi)" [a double-page spread], in Peltiset enkelit (Helsinki 1964), 32-33

$$
\text { 々) 々 々 }
$$

$\begin{array}{cllll}\text { Avoinna klo } 9-23 & & & \\ \text { HERNEROKKA } & 1.00 & \text { LIHAMUNAKAS } & 1.90 \\ \text { PAIST. SILAKAT } & 1.25 & \text { SIPULIPIHVI } & 3.00 \\ \text { LIHAPERUNALAATIKKO } & 1.50 & \text { VIENINLEIKE } & 3.00 \\ \text { LINDSTROMINPIHVI } & 1.55 & \text { KAURAPUURO } & 0.40 \\ \text { SEKALIHAPAISTI } & 1.75 & \text { LEIPA } & 0.18 \\ \text { LEIKKELELAUTANEN } & 1.90 & \text { VOI } & 0.24 \\ \text { SIANPAASYLTTY } & 1.30 & \text { MAITO } & 0.24\end{array}$

zodiac runoilijalla usein sykkivät suolet

Fig. 9.2 Kari Aronpuro, "Zodiac (aivofilmi)" [excerpt], in Peltiset enkelit (Helsinki 1964), 33 
the end of the list). Maybe the most expensive dishes, Wiener schnitzel or steak and onions (3.00 marks), spark the poem's speaker to add a less-than eloquent line underneath the menu: "a poet often has / pulsating bowels" ("runoilijalla usein / sykkivät suolet"). Instead of a romantic poet's pulsating heart, a modern poet seems to be driven by different, more material realities.

This is not the poem's only reference to poverty and hunger. Lower on the same page, there is another reference to memories of (wartime) poverty: "in the 40's when / we used to eat swede" ("40-luvulla kun / lanttua syötiin"). This cheerless root vegetable symbolizes everyday survival. Maybe this "history of hunger" is something that springs to the speaker's consciousness while seeing the range of all the unattainable dishes listed on the menu. Thus, a simple re-embedding of a list of foods to this text collage conveys an ideological significance.

This most probably authentic (a typographical facsimile) menu reflects the ethnographic impulse that collages also have: recording the everyday, unglamorous material, a canteen menu being one of the many mundane lists of the 1960s. This menu is not (originally) fictive or poetic, but it reproduces a pragmatic list and a certain, particular menu, discovered and graphically preserved. Here the list introduces a brief moment of (ironic) order in the midst of the wildly free multitude of graphical material that the collage presents.

The second menu is a poem by Kalevi Lappalainen (1940-1988), who had a rather peculiar, surrealistic style of writing. He lived in the USA between 1960-1964 and again from 1971 until his untimely death in a fire in 1988. His menu poem is a leap far from Aronpuro's realistic food list to more surreal servings. The effect of the form is different from Aronpuro's poem, where the list is embedded in the collage among all the other texts. In Lappalainen's text the list is the poem. It shows that the culinary list cannot only serve documentary purposes, but also convey culinary fantasy and imagination. Besides the title, which uses the word "menu," the reader also recognizes the form-the numbered listing, under which the servings are presented. Syntactically, the poem is a simple listing of dishes, but the contents of the menu are unusual, presenting an array of impossible foods and culinary phantasmagoria.

I WILL REVEAL MY FAVOURITE MENU 
I serving: Embalmed Nefernefernefer.

Some Jimi Hendrix rubbed in oil. One fried onion.

II serving: Fish grilled in lightning.

Hand soaked in water. Miss Almond tortured in fire.

III serving: Boiled astronaut.

Little birds and radishes. Waist with cucumber. (Lappalainen 1968, 53, original: "Paljastan teille himoruokalistani.")

The poem plainly presents a catalogue of objects, some of them referring to actual food (onion, fish, radishes, cucumber) while others refer to human beings. They are either fictitious (Nefernefernefer, a character in The Egyptian, a novel by Mika Waltari), real persons (Jimi Hendrix), cryptic allusions (Miss Almond), or just human body parts. Thus, in a gastronomical context of food and eating, the poem could be associated with anthropophagy - that is, cannibalism. However, further reading allows for a different interpretation which helps us to connect these bizarre combinations that seem enigmatic, disturbing, and confusing.

It is tempting to read the anthropophagic references and unconventional fusions as encoded erotic and sexual meanings. Eating and swallowing have a close relationship to physical love and eroticism, not just due to the oral dimension, but also because they symbolize procedures of internalizing, merging, and possessing. Framing normally inedible objects as edible, the poem relies on symbolic transference, where erotic impulses are converted into unexpected but powerful images. While some images exploit conventional romantic or erotic symbols (hand, little birds, waist, oil, perhaps a phallic cucumber), or otherwise clear references (Nefernefernefer, a deceitful woman who used her sexuality as a tool), some are more complicated. Both astronauts and Jimi Hendrix (at the peak of his career in 1968 renowned for his suggestive performances) were admired and adored by the masses, unlike the mysterious Miss Almond, who, instead of inner burning, is tortured in fire. Images of desire unite with weird, unappetizing images. Desire and disgust are close to each other, even "dialectically conjoined" (Ngai 2005, 332-333). Then again, Julia Kristeva's view on abjection - a strong, horrible disgust which shakes the foundations and boundaries of individual experience-is based on food and eating: food loathing is "perhaps the most elementary and most archaic form of abjection" (Kristeva 1982,2). The list form is apt for highlighting and mixing the cognitive categories: the poem becomes abject because it is situated at the border (see Kristeva 1982, 75) between 
eroticism, food consumption, and death or decay. It is the mixture which the poem suggests that troubles us. It suggests that we are attracted by what ultimately is also repulsive. The list as a formed order or the tradition of the menu stands in stark contrast to these surreal evocations of disgust that point toward the hidden and unconscious and not to the neatly formed and known.

Once again, the form of the list as the poem's structural idea reasserts itself in the title. The title also implies the erotic and libidinal contents of the poem, something that is in strong opposition to eating as "practical," mundane nutrition. Instead of "My Favourite Menu," for instance, the title uses specifically the word reveal, as if referring to something previously hidden. Additionally, the word himo used in the original title is closer to lust, desire, or addiction, than the milder term "favourite." This "lust menu" is thus the area for the poetic imagination, where charged images and associations surpass the culinary menu and result in strange, even repulsing, surrealist servings. This private and sexual usage clearly clashes with the social and culinary user function of a menu, connected with taste, hierarchy, and order-while maintaining the form. Disturbing images are listed in the menu form and thus set in conflict with the food references this form usually is used for. The orderly listing as such highlights the discrepancy between the poem's messages. For the reader, the numerical form and the cognitive setting of "menu" ties everything into an (almost) meaningful culinary frame of reference.

The next example is by Anselm Hollo (1934-2013), certainly the most renowned Finnish poet abroad, who lived in the USA from 1967 until his death. "Good Stuff Cookies" (circa 1968) is immediately recognized as relying on the form of a recipe: it utilizes the tripartite structure with the heading, the list of ingredients, and instructions. As is so often the case in lists, here, too, the reader immediately, even before reading anything, distinguishes and recognizes the numerical list as a visual unit, and thus sets it off from the rest of the poems in the collection. This recognition and the procedural nature inherent in the recipe form are quickly short-circuited in the reading, and the reader's attention on the list form turns poetic. Hollo's way of using spaces in the middle of the lines is also conspicuous. As is the case in the previous example, here, too, the familiar culinary format is exploited by filling it with something other than real foodstuffs. 
good stuff cookies

2 gods

$2 / 3$ cup hidden psychic reality

2 teasp. real world

$3 / 4$ cup sleep

2 cups sifted all-purpose iridescence

2 teasp. good stuff

$1 / 2$ teasp. pomp \& pleasure

beat gods hidden psychic reality

real world and sleep together

sift together iridescence good stuff

pomp \& pleasure

add to real world mixture

drop by teaspoon

2 inches apart on cookie sheet

press cookies flat

with bottom of glass dipped in sleep

bake at $400 \mathrm{~F} 8$ to 10 minutes

2 dozen cookies good stuff. (Hollo 1970, 98)

All ingredients are immaterial, spiritual substances. Unlike in Lappalainen's menu, there are no edible items in the mix. Beating two gods, hidden psychic reality, real world, and sleep together seem to be like a mixture for a philosophy of life. This is enhanced by the term "iridescence," meaning rainbow-like appearance of all the colors at once. While the form of the baking recipe strongly hints at a context of middle-class communality that values sugar-coated outward appearances, Hollo's recipe seems to aim at creating individualized truth and spiritual growth that transcend the need for material proof of the recipe's successful completion. A combination of religious, psychic, and sensuous dimensions makes one ask: what is this unspecified "good stuff" that seems to be both the aim, an ingredient, and an evaluation of the result? It is hard not to acknowledge the perspective of the late 1960s alternative or countercultural context and the advent of general societal liberation, which included also psychedelic drugs. This interpretation can be supported by the repetition of slang-like wording "stuff" (drugs, booze), as well as the well-known treats of hippie cuisine, cannabis cookies. Still, the interpretation should not solely stick to the 
countercultural dimension. The "good stuff" can be construed as the hidden motivator of all activity: the secret ingredient in any successful recipe that remains unwritten. The recipe form thus also means an activation of the reader, a reminder of a countercultural "do-it-yourself" ethics, an impulse to seek her own good stuff. The reader must decide whether this is a serious ideological theme, or just irony.

The final example is an exceptional drink recipe by M. A. Numminen (b. 1940), a versatile artist, singer, composer, and writer. It is a set of instructions for tea in six enumerated parts using a repetitive and cumulative structure. Every unit repeats the earlier unit, but also adds a new ingredient. Some of them are rarely used in kitchens.

\section{THE TRUE TASTE OF TEA}

I A genuine ceramic or porcelain pot is chosen. One spoonful of tealeaves is measured to the pot for each cup of tea. After this, boiling hot water is poured to the pot, and tea is left to brew from 3 to 5 minutes. Now tea is ready to be served.

II Tea is prepared as instructed in section I. Milk is boiled lightly in a separate pot, which can be made from any material, for instance from enamel, or stainless steel. Hot milk is poured into the cup first, only then the tea.

III Tea and milk are prepared as instructed in the sections I and II. Cloves are heated in hot, not boiling water. Some of this strong "clove extract" is poured to a heated cup. Also milk, and then tea is added.

IV Tea, milk, and "clove extract" are prepared as indicated in the sections I, II, and III. Room temperature vodka is heated by holding the bottle in hot water. First vodka, then "clove extract", milk, and tea respectively are poured into the cup.

V Tea, milk, "clove extract", and vodka are treated according to the instructions given in the sections I, II, III, and IV. Spoonful of dried horse manure is wrapped in tin foil, which is then heated. This "hashish" thus pulverizes into thin powder. The powder is sprinkled on the bottom of a warm cup, after which vodka, "extract", milk, and tea is added.

VI Tea, milk, "clove extract", vodka, and hashish are prepared as indicated in the sections I, II, III, IV, and V. By rubbing the penis manually, semen is drained to a warm cup. After this, the cup is further heated, to warm up the liquid. By stirring with a stick, the "hashis", vodka, "extract", milk, and tea is added. The beverage is now ready to drink. (Numminen 1971, 30-31, original: "Teen todellinen maku.") 
The recipe resembles historical recipes of the naturopathy, folk medicine, aphrodisiacs, or alchemy, where certain bodily elements like semen, sweat, or hair were thought to have great power when ingested. All the ingredients have strong symbolic value: tea is an ancient ceremonial substance, milk is indispensable for calves and babies, cloves have a reputation for increasing sexual potency, vodka intoxicates, sperm impregnates. The final addition of semen, in its solemnity, is a comical double-gesture: the most "precious" ingredient is added last, accompanied with helpful instructions on how to use it.

In terms of style the text uses the laconic and passive mood known from culinary recipes (the original uses deliberately outdated, "pedagogic" diction) and quite rigid, typographically recognizable listing with chapters and roman numerals. Here they seem to stand in radical contradiction to the contents, where the sociocultural and sexual norms are ironized cunningly by using a variety of means. First of all, the structure of repetition, accentuated by the numbered procedural catalogue, is crucial. It represents the accumulation of power and possible effect that increases with each new ingredient. Even though the recipe presents a description of one sequential process, there is also some overlap: the previous phases are repeated every time, like in six different recipes. This illuminates Belknap's definition of the list as "simultaneously the sum of its parts and the individual parts themselves" (Belknap 2004, 15). Furthermore, there are strange assimilations and discrepancies on the textual level. Part V introduces dried horse manure, calling it "hashis" with quotation marks, which later disappear. Clove extract is later called "extract" with quotation marks thus indicating that the substances go through a magical transformation or that the language itself might be coded, directed only to a select group. Eventually, even the title references esoteric knowledge: the true taste of a substance, in this case tea, is hidden knowledge: only a certain, rather complex and lengthy procedure can bring it to the fore.

\section{CONCLUSION}

When forms inspire writers, they duplicate and evolve in the poetic imagination. Across historical eras, forms not only carry continuity but also take on ever-shifting new meanings that can reflect back on the way those 
forms are used. The writer's horizon of imagination can reach beyond the limits posed by their own times: the list form always refers to and carries the history of non-literary writing, the form's universality in various areas of life-one of them culinary.

An obvious reason for the attraction of lists in experimental poetry is their affordance to perform the challenging play between order and chaos: the alleged unity (brought about by the form) and the countereffect, the free movement of verbal occurrences, and the "delight in unforeseen and unexpected combinations" (Belknap 2004, 5 ) it brings. The 1960s experimental scene was also a countercultural youth movement, so it is reasonable to see the lists in this context as devices to challenge and ironize social hierarchy and systems of symbolic order. When "food items and food consumption events are imbued with meanings of great significance" (Beardsworth and Keil 1997, 52), the culinary forms represent developed cultural rules, order, and taste, while they simultaneously stand for deeply human, physically inevitable activities of eating and drinking. Consequently, the form addresses three levels of experience: the personal, the culture specific, and the universal. ${ }^{11}$

All four culinary texts refer in different ways to sociocultural realities and norms of the 1960s. All of them state something, albeit in polysemic ways, about the relationship between the individual and society. All of them comment on the mundane, either embracing it (Aronpuro) or transcending it with fierce eroticism (Lappalainen) or clandestine intoxication (Hollo, Numminen). Aronpuro's poem embeds a menu in the semiotic world of text collage, lets it "speak for itself," and claims that lists are one of the everyday text formats that constitute our lives. The typographically sensitive collage poem also implies that lists are valuable, or interesting, because they highlight linguistic form as such. Lappalainen, Hollo, and Numminen take menu or recipe formulae to fill them with (personal) mythologies, sexuality, and "hidden psychic realities." The effect of all the individual poems is highly dependent on the list form and its procedural nature, which brings a structural irony to the provocative themes and contents. The texts imply that the use of the list form, for a writer, is a method to select information "from the mind-deep pool of possibility" (Belknap 2004, 19). The list is a formal resource or pattern that precedes the writing and channels it. The writer can embrace and enhance the possibly constraining aspects.

Enumeration can yield poetic effect and intensively meaningful efficacy; it can be used to create seductive, entertaining texts-or highly abstract, almost illegible textual objects. All my examples take a kind of non-serious, 
cerebral, and comical grasp to their subject matters, and even if a list can be said to be serious, the form seems to be most suitable for humorous purposes. Jan Alber's (2016) functions of lists in postmodernist fictionlinguistic self-reflexity, mocking the human need to bring order to chaos, and celebrating plurality - can, for the most part, be agreed upon with regard to the material discussed in this article. Alber's arguments also support the impression that literary lists have a kind of deeper, even penetrating, relationship to comicality.

My examples share a number of common features. In all of them (except in Aronpuro, where the list is embedded in a collage) the title is an important organizational principle as it guides the reader's perception of the text. Most examples (all but Numminen's text, which is a sequential compilation of instructive sentences, thus less list-like than the others) use vertical listings so that the typical list layout is immediately visible. Leafing through experimental poetry makes us realize the importance of the appearance of the list form in general. Lists can be ways to celebrate and embrace the visual dimension and the image-like attributes of texts. Also, in all the examples, the use of numerals is conspicuous. They play important roles in all four culinary texts as well as in "Scientific Facts" by Seilonen. Numbers and numerals seem to enhance the "listness" of the list by adding a deceptive sense of order or factuality - that is, by defamiliarizing poetry or literature through the introduction of elements commonly considered to be diametrically opposed to the realms of arts and aesthetics. In experimental poetry, the use of the list form often suggests omission or displacement of conventional literary means and characteristics: lists do not need a speaker, list-language usually does not create poetic imagery. In this way, in the context of (other) experimental techniques, the list form is a continuation of literature by other means.

\section{Notes}

1. Ouvroir de Littérature Potentielle (Workshop for Potential Literature, OuLiPo or Oulipo), a group concentrating on formal and mathematical resources for poetic activity, was established in 1960 by Raymond Queneau, François Le Lionnais, and others, and is still active with 20 living members. Instead of the Surrealists' interests on subconsciousness and total freedom, their take on creativity was considered a kind of "anti-Surrealism," fueled by strictly defined rules and repeatable procedures that were based on (or parodies of) mathematics, set theory, artificial languages, or other system- 
atic principles. The most important Oulipian concept is constraint, the rule that regulates and invigorates the creative process and shifts focus onto the act of writing. According to Harry Mathews, constraint "generates every work that can be properly called Oulipian" (Mathews and Brotchie 2005, 131). For information on OuLiPo, see Motte 2007, or Mathews and Brotchie 2005. For detailed readings on constrained writing, see the Poetics Today double issue (Baetens and Poucel 2009-2010). About the list form in the works of a pivotal Oulipian, Georges Perec, see Andrews 1996. For readings of four Oulipian literary recipes, see Joensuu 2021.

2. Besides food and drink, recipes also connect to the history of medicine, drugs, naturopathy, and esoteric areas of knowledge. Although Jack Goody $(1995,17)$ considers "the use of tables, lists, formulae and recipes" to be instances of "non-speech uses of language," recipes can also be drawn, acted out, filmed, or memorized.

3. One can think of culinary equivalents to all the basic types of listings as presented by R. E. Belknap (2004, 3-4): the list, the catalogue, the inventory, the itinerary and the lexicon. A recipe is a kind of itinerary, as it describes actions in temporal order. All these types can be exploited in fiction or poetry. Culinary inventories can be found in various literary works, from the novels of François Rabelais to Robinson Crusoe, from Ulysses to Gravity's Rainbow and Bridget Jones's Diary.

4. The Flounder by Günter Grass (1977) includes descriptions of meals, lists of their foodstuffs, and narrated recipes, often in blended fashion. In House of Day, House of Night by Olga Tokarczuk (1998), embedded recipes interrupt the narration. In Hortense Is Abducted by Jacques Roubaud (1987), a recipe is embedded in the narration in the old lyric format of sestina, recited by one of the characters.

5. Oulipo Compendium (Mathews and Brotchie 2005) is an encyclopedia of Oulipian methods, but includes no headwords for "list," "catalogue," nor "enumeration." Still, the list form is manifested in many of the examples involved therein.

6. Lipogram, like Georges Perec's novel La Disparation (1969), means omission of a certain letter. Thus, the writing process of La Disparation was regulated by the avoidance of all the French words that contained the letter "e." These forbidden words constitute a strictly defined, although invisible, lexicon-a word list that "haunts" the novel by its absence, so to say. In addition, one might claim that Robert E. Belknap's $(2004,15)$ definition of the list-a "formally organized block of information that is composed of a set of members"-sounds almost like a definition of any Oulipian text. Besides Oulipo, one can consider connections between the list form and other schools or approaches of experimental writing. A typology by J. M. Conte (1991, 214-237) divides postmodern poetry into serial and procedural poetry. The latter is divided into predetermined form and 
generative devices. It is legitimate to say that the list form can add both generative and predetermined aspects to writing. Still, in many cases of experimental writing, it implements a certain predetermined form.

7. For socio-cultural and historical context, see Eskelinen 2016, 247-269; Haapala 2007, 277-278.

8. While their historical emergence seems, at first glance, to fit well with McHale's (2008) dating of the genesis of postmodernism in 1966, the term's pertinence to the Finnish context is not evident. Even if the new literary generation of the 1960s diverged from certain aesthetic traits of the 1950s modernists (Veivo 2016, 773), both the preceding modernism and the aftermath were brief.

9. All translations in the article are by the writer, except "Good Stuff Cookies" by Anselm Hollo which was originally published in English.

10. Regarding lists, Mallander's poem also poses a question about the conceptual relationship between repetition and enumeration. Does a mere repetition of, say, a single word, constitute a list? Belknap's view on this is affirmative, although, according to him $(2004,34)$, a "repeated single item makes for a very boring list." This is not necessarily the case with concrete poetry or experimental literature.

11. In their own way, my examples also reaffirm affects and experientiality as a "crucial category for adequately describing and making sense of the processes that come into play when we encounter lists in literary texts" (von Contzen 2018, 316), although the content of these lists is not "practical."

\section{REFERENCES}

\section{Primary Sources}

Aronpuro, Kari. 1964. Peltiset Enkelit (Tin Angels). Helsinki: Kirjayhtymä.

Hollo, Anselm. 1970. Maya: Works 1959-1969. London: Cape Goliard Press.

Lappalainen, Kalevi. 1968. Puolihevosen Hermorata (Half Horse's Nerve Path). Hämeenlinna: Karisto.

Mallander, Jan Olof. 1969. Out. Helsinki: Söderström \& Co.

Numminen, M. A. 1971. Lastuja (Chips). Helsinki: Kirjayhtymä.

Polttila, Brita. 1966. Tapahtumista (On Occurrences). Helsinki: Tammi.

Seilonen, Kalevi. 1965. Tosiasioita minusta (Facts About Myself). Helsinki: Tammi.

\section{SeCONDARY Sources}

Alber, Jan. 2016. Absurd Catalogues: The Functions of Lists in Postmodernist Fiction. Style 50 (3): 342-358. 
Andrews, Chris. 1996. Puzzles and Lists: Georges Perec's Un Homme qui dort. MLN 111 (4): 775-796.

Baetens, Jan, and Jean-Jacques Poucel, eds. 2009-2010. Poetics Today 30: 4-31: 1: Constrained Writing I-II, Special Double Issue.

Beardsworth, Alan, and Teresa Keil. 1997. Sociology on the Menu: An Invitation to the Study of Food and Society. London/New York: Routledge.

Belknap, Robert E. 2004. The List: The Uses and Pleasures of Cataloguing. New Haven: Yale University Press.

Bray, Joe, Alison Gibbons, and Brian McHale. 2012. Introduction. In The Routledge Companion to Experimental Literature, ed. Joe Bray, Alison Gibbons, and Brian McHale, 1-18. London/New York: Routledge.

Conte, Joseph M. 1991. Unending Design: The Forms of Postmodern Poetry. Ithaca/London: Cornell University Press.

Epstein, Andrew. 2012. Found Poetry, "Uncreative Writing," and the Art of Appropriation. In The Routledge Companion to Experimental Literature, ed. Joe Bray, Alison Gibbons, and Brian McHale, 310-322. London/New York: Routledge.

Eskelinen, Markku. 2016. Raukoilla rajoilla: Suomenkielisen proosakirjallisuuden historiaa. Helsinki: Siltala.

Goody, Jack. 1995 [1977]. The Domestication of the Savage Mind. Cambridge: Cambridge University Press.

Haapala, Vesa. 2007. Kokeellinen kirjallisuus ja kirjallinen vastarinta Suomessa kiintopisteenä 1960-luku. In Kirjallisuuden avantgarde ja kokeellisuus, ed. Sakari Katajamäki and Harri Veivo, 277-304. Helsinki: Gaudeamus - Helsinki University Press.

Hottinen, Merja. 2016. Experiment, Scam, and Children's Games - The Finnish Media on Ken Dewey's Happenings in Finland, 1963-1964. In A Cultural History of the Avant-garde in the Nordic Countries 1950-1975, ed. Tania Orum and Jesper Olsson, 516-527. Leiden/Boston: Brill, Rodopi.

Hutcheon, Linda. 1994. Irony's Edge: The Theory and Politics of Irony. London/ New York: Routledge.

Joensuu, Juri. 2016. Vuoden 1965 mania? Suomalaisen kirjallisuuden hullu vuosi. Helsinki: Poesia.

Joensuu, Juri. 2021. Fictitious Meals, Culinary Constraints: The Recipe Form in Four Oulipian Texts. Poetics Today 42 (4): 575-595.

Kristeva, Julia. 1982. Powers of Horror: An Essay on Abjection. Trans. Leon S. Roudiez. New York: Columbia University Press.

Mathews, Harry, and Alastair Brotchie, eds. 2005. Oulipo Compendium: Revised \& U Udated. London/Los Angeles: Make Now Press, Atlas Press.

McHale, Brian. 2008. 1966 Nervous Breakdown, or, When Did Postmodernism Begin? Modern Language Quarterly 69 (3): 391-413. 
Motte, Warren. 2007. OULIPO: A Primer of Potential Literature. Trans. and ed. Warren Motte. Champaign/London: Dalkey Archive Press.

Ngai, Sianne. 2005. Ugly Feelings. Cambridge/London: Harvard University Press. Notaker, Henry. 2017. A History of Cookbooks: From Kitchen to Page over Seven Centuries. Oakland: University of California Press.

Veivo, Harri. 2016. Everyday High and Low - Finnish Avant-Garde Poetry of the 1960s in a Rapidly Changing Society. In A Cultural History of the Avant-garde in the Nordic Countries 1950-1975, ed. Tania Ørum and Jesper Olsson, 772-781. Leiden/Boston: Brill, Rodopi.

von Contzen, Eva. 2018. Experience, Affect, and Literary Lists. Partial Answers 16 (2): 315-327.

Open Access This chapter is licensed under the terms of the Creative Commons Attribution 4.0 International License (http://creativecommons.org/licenses/ by $/ 4.0 /)$, which permits use, sharing, adaptation, distribution and reproduction in any medium or format, as long as you give appropriate credit to the original author(s) and the source, provide a link to the Creative Commons licence and indicate if changes were made.

The images or other third party material in this chapter are included in the chapter's Creative Commons licence, unless indicated otherwise in a credit line to the material. If material is not included in the chapter's Creative Commons licence and your intended use is not permitted by statutory regulation or exceeds the permitted use, you will need to obtain permission directly from the copyright holder.

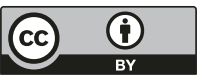

